\title{
Populismo y revolución en México: reflexiones en torno a los lenguajes políticos durante los años setenta
}

\section{Populism and Revolution in Mexico. Reflections on the Political Languages during the $70 \mathrm{~s}$}

\author{
ANA LUCÍA MAGRINI \\ Consejo Nacional de Investigaciones Científicas y Técnicas / \\ Centro de Historia Intelectual-Universidad Nacional de Quilmes / \\ Universidad Nacional de Río Cuarto / \\ analucia.magrini@gmail.com
}

Resumen: El populismo constituye un concepto polivalente y disponible en el lenguaje político latinoamericano desde mediados de los años cincuenta hasta nuestros días. A grandes rasgos, la trayectoria del concepto fue desde las primeras definiciones sustancialistas, en sus versiones más o menos axiológicas y anómalas, hasta los abordajes no sustancialistas producidos hacia finales del siglo Xx. El presente trabajo propone mostrar que hacia la década de los 70 de la mano de la renovación de la teoría marxista, del pensamiento revolucionario y del enfoque de la dependencia, la polisemia constitutiva del populismo se "enfrentó" a un proceso de significación inverso: la resustancialización de los conceptos. En un país como México, donde la Revolución Mexicana se constituyó como mito fundacional de un Estado que se auto-representó como popular y nacionalista, la emergencia del debate sobre el populismo requirió de un novedoso proceso de innovación conceptual. Así, este artículo propone realizar un abordaje históricoconceptual del populismo en México durante los años setenta, focalizando en los modos en que la constitución del concepto estuvo especialmente imbricada a la (re)significación de la Revolución.

Palabras claves: Lenguajes políticos, América Latina, Populismo, Revolución, México.

Abstract: Populism is a polyvalent concept and available in the Latin American political language from the mid-fifties until today. In general, the trajectory of the concept ranged from the first substantialist definitions, in their more or less axiological and anomalous versions, to the non-substantialist approaches produced towards the end of the $20^{\text {th }}$ century. The present article proposes to show that towards the decade of the 70's from the hand of the renewal of the Marxist theory, of the revolutionary thought and of the dependence approach, the constitutive polysemy of the populism "confronted" a process of inverse significance: the resubstantialization of the concepts. In a country like Mexico, where 
the Mexican Revolution was constituted as the founding myth of a state that represented itself as popular and nationalist, the emergence of the debate on populism required a new process of conceptual innovation. From there, this article tries to undertake a historical-conceptual approach to populism in Mexico during the seventies, focusing on the ways in which the constitution of the concept was especially imbricated to the (re)significance of the Revolution.

Keywords: Political languages, Latin America, Populism, Revolution, Mexico.

\section{Apuntes teóricos: los lenguajes políticos en América Latina}

Retomando parte del debate teórico reciente respecto a la relevancia de la dimensión discursiva en el marco de la denominada "nueva historia intelectual", la historia de los lenguajes políticos propone superar el estudio de la historicidad de los contenidos (ideas, doctrinas, conceptos, discursos, ideologías) para avanzar en el análisis de las formas y modos en que estos son producidos ${ }^{1}$. Desde este punto de vista, los lenguajes políticos son constitutivamente históricos y contingentes, cruzan el espectro ideológico y parten de una oposición entre ideas e ideologías. "A diferencia de las 'ideas', no son atributos subjetivos; los mismos articulan redes discursivas que hacen posible la mutua confrontación de ideas"2.

En un trabajo reciente, An Archaeology of the Political, Elías Palti ha argumentado que los lenguajes políticos son modos de producción de conceptos políticos ${ }^{3}$. A diferencia de "las palabras" y de "los términos", los conceptos políticos son constitutivamente polisémicos, no refieren a definiciones cerradas o estáticas sino que remiten a significantes históricos densos, que no pueden asociarse a un contenido concreto, por lo que su generalidad se enfrenta a la univocidad de las palabras ${ }^{4}$. Por ello, historizar conceptos políticos no es equivalente a establecer una "historia de las palabras" o de categorías teóricas. Para estudiar los lenguajes políticos debemos, además, reconstruir los contextos de debate sobre los que fue posible aquella polivalencia; es decir, aquellos supuestos y premisas sobre los que se configura el

\footnotetext{
${ }^{1}$ La historia de los lenguajes políticos se nutre de aportes de tres perspectivas que conforman la denominada "nueva historia intelectual": la escuela alemana o la historia de los conceptos de Reinhart Koselleck; la escuela anglosajona o escuela de Cambridge, específicamente las contribuciones de John G. A. Pocock y Quentin Skinner; y la escuela francesa o la historia conceptual de lo político de Pierre Rosanvallon. Ver: Palti, Elías, "Temporalidad y refutabilidad de los conceptos políticos", en Prismas, 9 (2005), pp. 19-34. Palti, Elías, "De la historia de 'ideas' a la historia de los 'lenguajes políticos' - las escuelas recientes de análisis conceptual: el panorama latinoamericano", en Anales, 7-8 (2005), pp. 63-81. «https://gupea.ub.gu.se/bitstream/2077/3275/1/anales 7-8 palti.pdf» [consultado el 14 de agosto de 2018].

${ }^{2}$ Palti, Elías, "Temporalidad y refutabilidad... op. cit., p. 32.

${ }^{3}$ Palti, Elías, An Archaeology of the Political. Regimes of Power from the Seventeenth Century to the Present, New York, Columbia University Press, 2017. Doi: https://doi.org/10.7312/palt17992

${ }^{4}$ Sigo aquí la definición de Reinhart Koselleck, quien especifica dos operaciones para el análisis históricoconceptual: el análisis diacrónico, que implica abordar un concepto a través del tiempo, y el sincrónico, que estudia un concepto en su contexto específico o puntual. No obstante, la plurivocidad de los conceptos solo puede advertirse en un estudio diacrónico. Koselleck, Reinhart, Futuro pasado, Barcelona, Paidós, 1993, p. 112.
} 
discurso público, que hacen posible la producción de diversas interpretaciones sobre un mismo significante y que obturan, inhiben o hacen inaudibles otras.

En este artículo nos interesa aproximarnos al abordaje de los lenguajes políticos entendiéndolos como gramáticas, lógicas de producción de sentidos sobre lo político que resultan especialmente perceptibles en determinados períodos y que, en circunstancias históricas concretas, no están exentas de tensiones, cambios, transformaciones o innovación. Lo específico de los lenguajes políticos, a diferencia de otros lenguajes, es que son constituidos por conceptos políticos tendencialmente polisémicos ${ }^{5}$. En definitiva, estos constituyen el léxico de los lenguajes.

Agrandes rasgos, el siglo xx podría caracterizarse como un formidable modo de producción de conceptos políticos polisémicos, entre los ejemplos más significativos podríamos mencionar: justicia social, revolución, populismo, liberación nacional, violencia, democracia, entre otros. Siguiendo las contribuciones más recientes de Palti, es posible advertir que, a diferencia del siglo XIX en el que el modo de producción conceptual se sostenía sobre la plena confianza en el progreso evolutivo o dialéctico de la Historia (en mayúscula), el xx se presenta como el período en el que la realización de esa promesa se volvería incierta; "el destino fue reemplazado por la política, y la política se convirtió en tragedia"6. Esa dimensión trágica secularizada involucró una relación distinta entre historia y sujeto. La historia podía y debía ser intervenida, torcida o forzada a través de una contundente acción subjetiva en el presente, una subjetividad militante y revolucionaria. Ciertamente, ello habilitó la afirmación de la violencia como un elemento constitutivo de la política.

Retomando el proyecto arqueológico foucaultiano, Palti sostiene que la matriz básica del siglo xx supuso el paso de la "Era de la Historia" a la "Era de las Formas", proceso perceptible no solo en el pensamiento político, sino también en el arte, en las ciencias naturales y en las humanidades. Lo crucial en este lenguaje político no eran las "leyes universales" ni los contenidos esenciales de los conceptos, sino sus formas y relaciones (desustancialización de los conceptos). En ciertos contextos, la producción de contenidos no sustancialistas de los conceptos estuvo aparejada a una suerte de resustancialización de sus formas ${ }^{7}$. En las últimas décadas del xx, el proceso de desustancialización se profundizó habilitando la emergencia de la contingencia y haciendo posible la identificación de acontecimientos que podían desestabilizar, tanto los contenidos como las formas de los conceptos políticos. Llegada esta instancia, las formas perderían su carácter esencial, estable o estático.

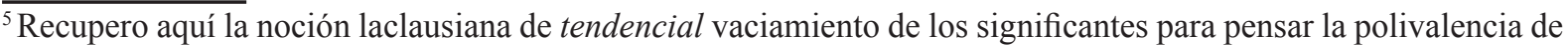
los conceptos políticos. En la teoría política del discurso, la lógica de lo tendencial supone que no hay significantes en sí mismos "vacuos" sino que el vaciamiento involucra un proceso en el que, bajo ciertas condiciones contextuales, los significantes comienzan a representar a otros, a excederse en sus contenidos concretos y a volverse algo más que sí mismos. Laclau, Ernesto, La razón populista, Buenos Aires, Fondo de Cultura Económica, 2005.

${ }^{6}$ Palti, Elías, An Archaeology... op. cit., p. 189. Traducción del autor.

${ }^{7}$ Palti ejemplifica la desustancializacion de los contenidos y la resustancialización de las formas a través del concepto de democracia en la teoría pura del derecho de Hans Kelsen. Ver: Kelsen, Hans, Esencia y valor de la democracia, Madrid, Guadarrama, 1977 [1929].
} 
El populismo podría pensarse como un ejemplo de este desplazamiento en los modos de producción conceptual. La trayectoria que el significante siguió en América Latina fue de las primeras definiciones sustancialistas a los abordajes no sustancialistas. En las versiones más o menos axiológicas y anómalas, la "esencia" de los fenómenos tipificados como populistas se depositaba en una serie de contenidos históricos y/o políticos concretos: como el tipo de liderazgo, las características peculiares del proceso de modernización o del tipo de desarrollo de los países del llamado Tercer Mundo, "ideologías demagógicas", entre otros aspectos. Hacia fines del siglo xx comenzaron a producirse en nuestra región conceptualizaciones no esencialistas y no peyorativas del populismo, las cuales disputaron y se yuxtapusieron a la producción conceptual anterior ${ }^{8}$. Estos nuevos modos de conceptualizar el populismo propusieron un abordaje que desplazó la mirada de los contenidos a las formas, de la esfera del deber ser a la esfera del ser de la política, de la especificidad histórica de los fenómenos populistas a la negación de una especificidad temporal preestablecida, de la limitación de los populismos como fenómenos eminentemente latinoamericanos o tercermundistas a la negación de tal singularidad espacial.

Ahora bien, desde el punto de vista del análisis sincrónico resulta perceptible que aquel paso de la sustancialización a la desustancialización del concepto de populismo no fue tan lineal, ni estuvo exenta de tensiones. Incluso en los debates más recientes aparecen con frecuencia supuestos esencialistas y peyorativos respecto a los fenómenos populistas propiamente dichos así como a la "base social" que los sustenta. Por ello, nos proponemos aquí analizar cómo opera aquella gramática o lenguaje político que caracterizaría al siglo xx en una coyuntura específica: México durante los años setenta.

La propuesta se desprende de un proceso de investigación más amplio que actualmente se encuentra en curso 9 . En la mencionada pesquisa consideramos central indagar las relaciones entre los lenguajes políticos, el concepto de populismo y sus referentes históricos concretos, esto es, las experiencias políticas tipificadas como populistas pues atender a los vínculos entre los modos de producción conceptual y la resignificación de experiencias políticas pasadas nos permitirá comprender cómo fue que en América Latina experiencias como el peronismo en Argentina, el cardenismo en México o el gaitanismo en Colombia, por nombrar algunos ejemplos, han sido iterativamente tematizadas, teorizadas y problematizadas ${ }^{10}$.

El presente artículo se estructura en dos partes, en la primera, se exhibe una génesis del debate sobre el populismo en América Latina, desde su gestación hasta los años setenta. En la

\footnotetext{
$\overline{{ }^{8} \text { Recuperando el }}$ pensamiento gramsciano y apartándose de la teoría de la modernización y de la perspectiva dependentista, a finales de los años setenta se produjo en Argentina una conceptualización no peyorativa del populismo. Nos referimos a la obra de Ernesto Laclau, Política e ideología en la teoría marxista. Capitalismo, fascismo y populismo, Madrid, Siglo XXI, 1980 [1977]. En trabajos posteriores el autor profundizó en su abordaje del populismo como forma de lo político. Ver: Laclau, Ernesto, La razón populista ... op. cit.

${ }^{9}$ Investigación en el marco de la Carrera de Investigador Científico y Tecnológico del Consejo Nacional de Investigaciones Científicas y Técnicas (CONICET).

${ }^{10}$ En otro lugar me detuve en los modos en que dos conceptos polisémicos, el populismo en Argentina y la(s) Violencia(s) en Colombia, fueron producidos a partir de la iterativa (re)significación de dos experiencias políticas disímiles, el primer peronismo y el gaitanismo. Magrini, Ana Lucía, Los nombres de lo indecible: populismo y Violencia(s) como objetos en disputa, Buenos Aires, Prometeo, 2018.
} 
segunda, se realiza un análisis histórico-conceptual del populismo y del concepto de revolución en México focalizando en una interpretación que inauguró el mencionado debate: la obra de Arnaldo Córdova. Al final, se identifican hallazgos y conclusiones preliminares respecto a algunas tensiones que el análisis propuesto plantea para el estudio del populismo y de los lenguajes políticos en América Latina.

\section{Populismo, la génesis de un debate}

Como muchos otros conceptos, el populismo fue traducido, resignificado y especialmente intervenido en América Latina. Hacia mediados de los años cincuenta el concepto da "un salto" a las Ciencias Sociales. Ciertamente Argentina fue uno de los primeros países de producción conceptual. Allí el populismo emergió tempranamente y, de la mano de la renovación de la sociología científica y de la obra de Gino Germani, se convirtió en la principal explicación al peronismo luego de su caída (1955).

Dos perspectivas en boga, el funcionalismo y la teoría de la modernización, nutrieron las primeras conceptualizaciones del populismo en clave sociológica. Desde este clivaje teórico, los países latinoamericanos se habían apartado del curso "normal de la historia". En realidad lo que parecería ser una característica peculiar de la desviación latinoamericana era el carácter acelerado y asincrónico del cambio social y del proceso de transición de la sociedad tradicional a la moderna. Lo asincrónico remitía a la presencia de elementos tradicionales y modernos distribuidos de manera desigual en estas sociedades. El contraste entre regiones desarrolladas y no desarrolladas, se combinaba con un proceso de movilización social acelerada, que superaba la capacidad del sistema político de integrar a las nuevas clases trabajadoras recientemente proletarizadas. Estos sectores, al no ser representados por las instituciones tradicionales, como sindicatos y partidos políticos, quedaban en situación de disponibilidad pudiendo ser manipulados e incluidos a la vida política bajo formas autoritarias y de pseudo participación democrática. Bajo este prisma, el populismo era una respuesta -efectiva y autoritaria- al problema de la integración de las masas en sociedades en transición ${ }^{11}$.

Una interpretación claramente receptora de la definición germaniana del populismo y que profundizó aspectos como la ideología y la relación líder-masa, fue la perspectiva de Torcuato Di Tella. Conforme con Di Tella, para la formación de un movimiento populista, no era suficiente la presencia de una "masa disponible" "fuertemente cargada de recientes inmigrantes del campo" (hasta aquí llegaba el argumento inicial de Germani); sino que se requería, además,

\footnotetext{
${ }^{11}$ Germani, Gino, Política y sociedad en una época de transición, Buenos Aires, Paidós, 1962 [1956]; Germani, Gino, Autoritarismo, fascismo y populismo nacional, Buenos Aires, Temas, 2003 [1978].
} 
de "una ideología o una psicología dominante típica suficientemente difundida como para desempeñar las funciones de comunicación y generación de entusiasmo" ${ }^{12}$. En definitiva, el populismo consistía en "un movimiento político con fuerte apoyo popular, con participación de sectores de clases no obreras con importante influencia en el partido, y sustentador de una ideología anti-status quo"13. Las "ideologías demagógicas" jugaban aquí un papel importante como "medio de control social y movilización de las masas", ya que de lo contrario las clases altas y medias no podrían "canalizar las masas en su favor"14.

Estas primeras formulaciones del concepto partían de dos elementos que se presentaban como datos indiscutibles: la presencia de un tipo de liderazgo carismático y una "base social" sobre la que este se asentaba. Dicha base era tematizada, cuantificada y analizada como un "hecho social" al tiempo que era significada bajo representaciones del pueblo masa. Si bien, la sociedad de masas no tenía per se un carácter negativo, al menos en la formulación de Germani, el carácter peyorativo de lo masivo se escondía tras el peligro de la puesta en crisis de los modos de integración y de los valores tradicionales que producía la sociedad de masas, especialmente en los países en vías de desarrollo ${ }^{15}$.

La obra de Elías Canetti, Masa y poder, estaba en la base de las connotaciones peyorativas sobre las masas de las primeras formulaciones del populismo. para Canetti la masa tenía vida propia, una voluntad aparte de los individuos que la conformaban. El autor tipificó distintos "tipos de masas" que se producían en determinados contextos y circunstancias, sin embargo en todas ellas la individualidad se perdía en el proceso de homogenización masivo. Esto llevaba a los individuos a unirse a ellas a través del contagio, movilizados por impulsos destructivos. El impulso a la destrucción era en realidad una reacción a un sentimiento persecutorio. Aplicado a fenómenos políticos, la adhesión de las masas a un líder carismático era comprensible por "el temor a desintegrarse, que siempre está vivo" en la masa y "hace posible orientarla hacia objetivos cualesquiera" $"$.

Hacia los años sesenta el pensamiento desarrollista, que venía produciéndose en la región desde mediados de los cincuenta, había propiciado la división dualista entre dos tipos ideales de comunidades: los países "desarrollados" y la porción del mundo que se desviaba de ese modelo de desarrollo, los países "subdesarrollados" o en vías de desarrollo. La lógica de esta perspectiva no era nueva, parecía una versión más sofisticada y economicista de la teoría de la modernización.

\footnotetext{
${ }^{12}$ Di Tella, Torcuato, "Ideologías monolíticas en sistemas políticos pluralistas: el caso latinoamericano", en Di Tella, Torcuato et al., (eds.), Argentina, sociedad de masas, Buenos Aires, EUDEBA, 1971 [1965], p. 274.

${ }^{13}$ Di Tella, Torcuato, "Populismo y reformismo", en Germani, Gino et al. (eds.), Populismo y contradicciones de clase en Latinoamérica, México, Era, 1977 [1973], p. 47.

${ }^{14}$ Ibídem, pp. 46-47.

${ }^{15}$ Germani, Gino, "Anomia y desintegración social", en Blanco, Alejandro, Gino Germani: La renovación intelectual de la sociología, Buenos Aires, Universidad Nacional de Quilmes, 2006 [1945], pp. 55-72.

${ }^{16}$ Canetti, Elías, Masa y poder, Barcelona, Muchnick Editores, 1981 [1960], p. 24. Cursiva propia.
} 
La CEPAL, el principal ámbito de producción intelectual del desarrollismo ${ }^{17}$, proponía una serie de alternativas para que los países subdesarrollados alcanzaran el nivel de desarrollo deseable, estrategias como la industrialización a través del sistema ISI, por sustitución de importaciones, fueron las principales herramientas difundidas por la CEPAL. El modelo suponía que había una serie de medidas que los países subdesarrollados debían adoptar para desarrollarse, ello involucraba prácticas institucionales que debían seguirse con especial supervisión del Primer Mundo. La noción de Tercer Mundo, producto de la finalización de la Segunda Guerra Mundial y de la Guerra Fría, sirvió de base argumental a esta perspectiva. Para Arturo Escobar ${ }^{18}$ el concepto caló hondo en los estudios latinoamericanos, se articuló tanto a las teorías del desarrollo como de la dependencia, e incluso a la perspectiva marxista, amén de que había sido alimentado por los intereses norteamericanos en la región y en los países recientemente independizados de África y Asia.

Conforme las estructuras socio-económicas de los países del llamado Tercer Mundo fueron mostrando severas dificultades para alcanzar los objetivos del modelo, la teoría cepalina fue incluyendo algunas modificaciones en su proyecto inicial, como la necesidad de avanzar a una etapa de sustitución de importaciones de bienes intermedios y de capital. No obstante, América Latina parecía inmune a las medidas diseñadas. Dichas limitaciones habilitaron el tránsito a un enfoque más radical, que propuso analizar firmemente las restricciones estructurales que el capitalismo mundial planteaba para los países "subdesarrollados".

Del proyecto cepalino surgió su propia crítica: el enfoque de la dependencia ${ }^{19}$. La mirada dependentista no fue homogénea y supuso una relectura "de la narrativa desarrollista en clave socialista o rupturista, que colocaba en el centro al Estado-nación, y en la meta el desarrollo autónomo" ${ }^{20}$. Los principales ámbitos de producción conceptual de la dependencia fueron Brasil, Chile y México, aunque la hipótesis de la dependencia tiñó casi toda la producción teórica progresista en América Latina hasta finales de los setenta ${ }^{21}$. Desde una crítica al sistema capitalista que se nutría de un variado andamiaje conceptual marxista, el dependentismo denunciaba la dominación económica, cultural y política de los países centrales frente a los periféricos. La vía desarrollista constituía un camino contraproducente para la emancipación

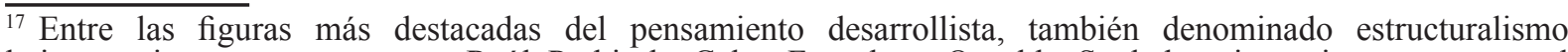
latinoamericano, se encuentran Raúl Prebisch, Celso Furtado y Osvaldo Sunkel, quienes jugaron un papel significativo en la producción teórica y empírica sobre América Latina en la Comisión Económica para América Latina y el Caribe (CEPAL), organismo dependiente de Naciones Unidas.

${ }^{18}$ Escobar, Arturo, La invención del Tercer Mundo. Construcción y deconstrucción del desarrollo, Caracas, Ministerio del Poder Popular para la Cultura, 2007.

${ }^{19}$ Siguiendo a Beigel queremos resaltar la dificultad de referirse a esta perspectiva como una "única teoría sistemática". Beigel, Fernanda (dir.), Autonomía y Dependencia académica: Universidad e investigación científica en Argentina y Chile: 1950-1980, Buenos Aires, Biblos, 2010, p. 129.

${ }^{20}$ Svampa, Maristella, Debates latinoamericanos. Indianismo, desarrollo, dependencia y populismo, Buenos Aires, Edhasa, 2016, pp. 203-204.

${ }^{21}$ Conforme con Svampa, Brasil proporcionó "los principales referentes intelectuales de la dependencia" (Fernando Henrique Cardoso y Ruy Mauro Marini son posiblemente las figuras más destacadas); México funcionó como "país refugio" luego del golpe de las Fuerzas Armadas en Brasil (1964); y Chile se convirtió "en un fenomenal laboratorio político" hasta la caída de Salvador Allende en 1973. Svampa, Maristella, Debates ... op. cit., pp. 203204.
} 
y la liberación de la condición dependiente de los países periféricos. Ninguna alternativa que no atacara de raíz el problema de la dependencia, que era sustancialmente estructural, podría resultar una vía real de cambio social.

Más que cuestionar la dualidad entre sociedades tradicionales y modernas, desarrolladas y subdesarrolladas, el dependentismo antepuso y resignificó el binomio centro y periferia ${ }^{22}$. Ello habilitó el retorno del debate sobre el populismo en la región e introdujo, a través de la dependencia, una versión ya no explícitamente anómala pero sí fuertemente crítica de las experiencias populistas. Aquello que había sido considerado en las primeras formulaciones de los teóricos de la modernización como una forma de anomalía política, comenzó a ser incorporado como un aspecto constitutivo de un proceso histórico peculiar latinoamericano, el de las sociedades dependientes. La condición de Estado y sociedad dependientes expresaba "la subordinación de las estructuras económicas (y no solo de ellas, puesto que hay otras que la refuerzan y la hacen posible: política, cultura) al centro hegemónico"23.

Los teóricos dependentistas compartían con la teoría de la modernización la idea de que el populismo representaba una fase en la historia del desarrollo en América Latina. El populismo designaba una alianza interclasista entre sectores populares proletarios, clases medias y burguesías nacionales en contra de los regímenes oligárquicos. El populismo se manifestaba como una tendencia nacional-desarrollista, un reformismo limitado que no superaría las barreras estructurales de la dependencia. En realidad lo que estaba en la base de la crítica al populismo ya no era el carácter "irracional" o anómalo de las masas, sino las limitaciones del reformismo.

El sociólogo e investigador brasileño Octavio Ianni profundizó en este rasgo del populismo e hizo especial énfasis en la constitución de un Estado populista ${ }^{24}$. Recuperando el enfoque dependentista, Ianni sostuvo que el "populismo latinoamericano corresponde a una etapa determinada de la evolución de las contradicciones entre sociedad nacional y la economía dependiente" 25 . En dicha etapa se habían producido alianzas entre las burguesías nacionales y los sectores populares en la región con el objetivo de desarticular las viejas oligarquías agroexportadoras (Estado oligárquico). En comparación con otros Estados populistas latinoamericanos, lo singular del caso mexicano era que allí, "el populismo surgió como un subproducto de la revolución", y en "la medida en que el proceso revolucionario culmina en el cardenismo, la política de masas aparece como una regresión política [...]; el cardenismo surge en la izquierda y avanza hacia la derecha en la importantísima combinación entre partido

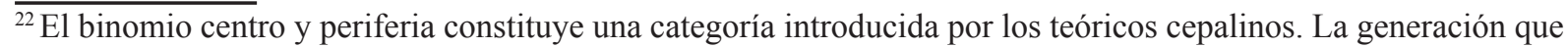
transitó al dependentismo, como Theotonio Dos Santos, André Gunder Frank, Aníbal Quijano, Vania Bambirra, Ruy Mauro Marini, Fernando H. Cardoso y Enzo Faletto, entre otros, articularon el mencionado binomio a la matriz marxista y lo releyeron en clave de dominación.

${ }^{23}$ Cardoso, Fernando y Enzo Faletto, Dependencia y desarrollo en América Latina, Buenos Aires, Siglo XXI, 1971 [1969], p. 192.

${ }^{24}$ Ianni, Octavio, La formación del Estado populista en América Latina, México, Era, 1975.

${ }^{25}$ Ianni, Octavio, "Populismo y relaciones de clase", en Germani, Gino et al., Populismo y contradicciones de clase... op. cit., p. 85.
} 
y Estado"26. Para Ianni, el cardenismo constituía la expresión nacionalista y desarrollista en la que se sometieron dos "tendencias polares (la lucha de clases y la alianza de clases)", en dicha alianza predominaría la defensa del orden burgués. Por ello, el "partido de la revolución" en México se fue adaptando y cambiando de nombre varias veces ${ }^{27}$. Para el autor, la característica esencialmente antirrevolucionaria del populismo se visualizará en México con más fuerza durante los gobiernos posteriores a Cárdenas (1934-1940), período en el que se "restablecen y desarrollan relaciones económicas de cooperación con Estados Unidos" y en que "renace [...] el modelo de desarrollo dependiente" ${ }^{28}$.

Ianni propuso un enfoque centrado en el análisis de las dimensiones estructurales del populismo, en él eran significativas las "estructuras de poder", "las relaciones de clases" y "los encadenamientos entre relaciones económicas y políticas" ${ }^{29}$. Al prestar atención a estas dimensiones así como a las relaciones entre sindicatos, partidos y Estado, su perspectiva fue especialmente recuperada para el análisis de la experiencia mexicana ${ }^{30}$.

En suma, la connotación peyorativa que subsistía en las nociones de populismo en clave anómala sufrió una interesante transformación a inicios de la década de los 70 . Durante esta década lo periférico y lo dependiente, resultaron una representación atractiva, pues permitía revalorizar el papel combativo de clases subalternas frente al imperialismo.

Dijimos antes que el modo de producción conceptual del siglo xx involucró un nuevo sentido de la historia, en el cual su evolución requería de una fuerte intervención subjetiva para "forzarla" y hacer posible el cambio social. Ello introdujo un nuevo problema: quiénes podían y debían llevar adelante dichas transformaciones, qué proyectos resultaban deseables y cuáles no. Durante los setenta, el sujeto popular comenzó a asociarse a representaciones no peyorativas. Ello supuso una relectura de "las masas", "el pueblo trabajador", "la clase obrera", "el pueblo campesino", "las clases populares". El pueblo periférico se convirtió en la figura predilecta que podía llevar adelante un proyecto "verdaderamente revolucionario". La violencia era entendida como una herramienta política más del pueblo para liberarse de una violencia estructural y anterior, la económica, la estatal y la gubernamental. En manos del pueblo, la violencia lograría producir una contundente "torsión" de las barreras y límites estructurales de la historia ${ }^{31}$. Pero no toda violencia podía parir "la otra historia", solo aquella que se orientara a la verdadera lucha emancipadora era legítima y la verdadera lucha emancipadora consistía en el desmantelamiento

\footnotetext{
${ }^{26}$ Ibidem, p. 88 .

${ }^{27}$ Desde su fundación, en 1929, hasta 1937 se denominó Partido Nacional Revolucionario (PNR), desde entonces hasta 1945 asumió el nombre de Partido de la Revolución Mexicana (PRM) y, desde 1945 en adelante, Partido Revolucionario Institucional (PRI).

${ }^{28}$ Ianni, Octavio, "Populismo y relaciones de clase... op. cit., p. 135.

${ }^{29}$ Ianni, Octavio, La formación del Estado... op. cit., p. 10.

${ }^{30}$ Ejemplo de ello es la obra del investigador español Entrena Durán, Francisco, México: del caudillismo al populismo estructural, Sevilla, Escuela de Estudios Hispanoamericanos, 1995.

${ }^{31}$ El libro de Fanon, Los condenados de la tierra, fue un texto que tuvo una amplia recepción en Latinoamérica y cuyos argumentos en favor de la descolonización de Argelia fueron adaptados e intervenidos para pensar el uso de la violencia como instrumento legítimo de la lucha política. Fanon, Frantz, Los condenados de la tierra, México, Fondo de Cultura Económica, 1965 [1961].
} 
de las condiciones estructurales del capitalismo, el imperialismo y la dependencia. De allí la intensidad de los debates respecto a cómo definir el contenido de la liberación nacional ${ }^{32}$.

En aquellos países en los que la cuestión rural ocupó un papel central, como Colombia ${ }^{33} \mathrm{y}$ México, la figura del pueblo campesino se colocó en primer plano. El campesinado fue definido como el sujeto eminentemente popular y esencialmente revolucionario, verdaderas mayorías, étnica y culturalmente diversas, que llevarían adelante la tarea revolucionaria a escala nacional y regional.

En México, donde la idea de revolución resultó fundacional en el relato nacional al menos para la historiografía oficial, hacia los años setenta comenzó a producirse un concepto de populismo que puso en discusión la médula de ese relato. El populismo se definió inicialmente como el producto, ya no de una revolución social frustrada (Colombia), sino como el resultado de una revolución populista. De ella se desprendían otras expresiones también tipificadas como populistas, el caso ejemplar fue el cardenismo.

\section{México, la emergencia del populismo y la (re)significación de la Revolución}

Los setenta fueron años convulsionados, marcados por la lógica de la Guerra Fría, la emergencia del clima de ideas revolucionarias propiciadas por dos experiencias socialistas en la región, una exitosa y producida a través de la lucha armada, Cuba (1959), y otra de corta duración, nacida de la lucha democrática, Chile (1970-1973). Otras experiencias emancipadoras a nivel mundial, como la independencia de Argelia (1954-1962) y las guerras de liberación nacional en Asia y África, contribuyeron a activar el pensamiento revolucionario y una diversidad de articulaciones con perspectivas de izquierda.

Durante estos años el concepto de populismo funcionó como un vehículo para discutir proyectos políticos entre alternativas posibles, entre ellas se encontraban: las dictaduras civiles y militares, el camino al socialismo (por vía revolucionaria o democrática), las democracias liberales y el "reformismo" populista. Aunque a mediados de la década las alternativas políticas parecían reducirse a dos: dictadura o revolución. En este abanico de proyectos posibles y/o

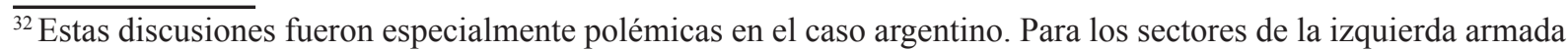
peronista la lucha por el retorno de Perón era la única violencia legítima que llevaría a la liberación nacional, mientras que para otros sectores de izquierda armada no-peronistas precisamente el peronismo representaba un límite para la emancipación.

${ }^{33}$ En Colombia, un país marcado por la ausencia de una revolución social efectiva, a inicios de la década de los 70 Marco Palacios formulaba el primer ensayo científico sobre el "populismo fallido". Palacios, Marco, El populismo en Colombia, Bogotá, Siuasinza, 1971. Ver: Magrini, Ana Lucía, "Colombia y los nombres de lo político. Populismo, Violencia(s) y gaitanismo", en Revista Iberoamericana. América Latina - España - Portugal, 63 (2016), pp. 34-52. «https://journals.iai.spk-berlin.de/index.php/iberoamericana/article/viewFile/2132/1889»" [consultado el 14 de agosto de 2018]; y Magrini, Ana Lucia, Los nombres de lo indecible ... op. cit., pp. 261-286.
} 
deseables, el populismo se convertía en un reverso y en un límite para las democracias. No es casual que la multicitada obra de Ionescu y Gellner comenzara remitiendo al populismo como un fantasma que podría sustituir a "la amenaza comunista" 34 . En México, el debate sobre el populismo volvió a poner sobre el tapete un peculiar límite tanto para una democracia sustantiva como para una "revolución verdadera".

A cuatro años de la matanza de Tlatelolco, movilización estudiantil y obrera que terminó en una feroz represión en Ciudad de México, Arnaldo Córdova publicaba un libro breve pero contundente, cuyo argumento principal habilitó la emergencia del debate sobre el populismo en su país: La formación del poder político en México ${ }^{35}$. La obra fue editada por Era $^{36}$ y reimpresa al menos veintisiete veces entre 1972 y el 2005. Dos años después de su aparición, la misma casa editorial publicó La política de masas del cardenismo ${ }^{37}$. Entre la aparición de ambos textos Era editó un tercer libro de Córdova: La ideología de la Revolución Mexicana ${ }^{38}$.

Las mencionadas obras fueron producidas en el marco de una vasta discusión sobre el carácter utópico de la democracia en México $^{39}$ y sobre la identificación del régimen político mexicano como formalmente democrático aunque signado por rasgos autoritarios, tanto en el ejercicio del poder real como en las limitaciones formales a las reglas de juego de la competencia electoral. El movimiento estudiantil del 68, y otros sectores como el movimiento médico de 1965, habían hecho posible esta crítica habilitado la articulación entre protestas sociales y la denuncia sobre la democracia aparente. La salida del gobierno de Gustavo Díaz Ordaz (19641970), responsable de la represión sistemática al movimiento estudiantil y la designación de Luis Echeverría Álvarez como su sucesor en las elecciones presidenciales de 1970 reafirmaron la continuidad de formas autoritarias de gobierno. Si bien en su enunciación pública Echeverría se presentaba como un líder que proponía suturar el conflicto estudiantil, las prácticas represivas y los atentados a los derechos humanos fueron habituales durante su gobierno ${ }^{40}$.

La denuncia no era nueva ${ }^{41}$, lo que sí constituía una innovación era la identificación de un régimen político que desde Porfirio Díaz se caracterizaba por la transmisión del mando (sucesión presidencial) y en el que, paradójicamente, las masas populares eran incorporadas en el seno

\footnotetext{
${ }^{34}$ Parafraseando a Marx y Engels, los autores comenzaban su obra con la siguiente frase: "Un fantasma se cierne sobre el mundo: el populismo". Gellner, Ernest e Ionescu, Ghita (comps.), Populismo. Sus significados y características nacionales, Buenos Aires, Amorrortu, 1969, p. 7.

${ }^{35}$ Córdova, Arnaldo, La formación del poder político en México, México, Era, 2005 [1972].

${ }^{36}$ En 1960 Neus Espresate Xirau, inmigrante española radicada en México en 1946, funda junto a otros intelectuales críticos, la casa editorial Era, proyecto que pronto se convirtió en un centro de difusión del marxismo independiente y de la nueva izquierda.

${ }^{37}$ Córdova, Arnaldo, La política de masas del cardenismo, México, Era, 1974.

${ }^{38}$ Córdova, Arnaldo, La ideología de la Revolución Mexicana, México, Era, 1973.

${ }^{39}$ Ver, por ejemplo, Zermeño, Sergio, México: una democracia utópica. El movimiento estudiantil del 68, México, Siglo XXI, 1978.

${ }^{40}$ Echeverría recibió dos órdenes de aprehensión por delitos de lesa humanidad con prisión domiciliaria. La Fiscalía Especial para Movimientos Sociales y Políticos del Pasado determinó indiciar su responsabilidad en la matanza de Tlatelolco del 68, la matanza estudiantil de 1971 y la desaparición forzosa de personas. Finalmente fue absuelto de todos los cargos en el 2009.

${ }^{41}$ En un ensayo de 1947 Cosío Villegas había alertado el extravío del rumbo revolucionario en la democracia mexicana. Cosío Villegas, Daniel, La crisis en México, México, Clío, 1997 [1947].
} 
del Estado desde la hegemonía de un partido auto-representado como "revolucionario". A esta última interpretación contribuyó considerablemente la obra de Arnaldo Córdova.

Arnaldo Córdova (1937-2014) hace parte de una franja de intelectuales críticos cuya discursividad se caracterizó por apelar a la matriz marxista, por mantenerse relativamente al margen de las directrices del Partido Comunista Mexicano (PCM) y por adoptar de un posicionamiento crítico o distante respecto al clivaje estalinista. En palabras de Carlos Illades, el autor del La formación del poder político en México perteneció a la cuarta generación de intelectuales marxistas mexicanos. Esta generación construyó un marxismo más pluralista, marcado la irrupción de la nueva izquierda y la renovación teórica producida a la luz de la recepción del pensamiento gramsciano y althusseriano ${ }^{42}$. Córdova conformó el grupo fundador de dos proyectos editoriales colectivos que dan cuenta de las formas diversas en que la teoría marxista fue recuperada en México: la revista de izquierda (no ortodoxa), Cuadernos Políticos (1974-1990) y Nexos (1978 en adelante), revista de centro-izquierda que sobrevivió a la crisis del marxismo y al colapso del comunismo ${ }^{43}$.

El alejamiento del PCM no implicó para este sector de la intelectualidad mexicana la renuncia al proyecto revolucionario, por el contrario, las reflexiones en el orden teórico, en términos de cómo "adaptar", "traducir" o "intervenir" la teoría marxista, se orientaron precisamente a producir cambios fundamentales en las estructuras sociales, políticas y económicas locales. En este sentido, el proyecto intelectual de Arnaldo Córdova guardó una especial conexión con el que, una generación atrás, había iniciado Pablo Gonzáles Casanova. En efecto, en 1968, Córdova se incorporaría al Instituto de Investigaciones Sociales de la UNAM bajo la dirección de Gonzáles Casanova.

A diferencia de la perspectiva sociológica introducida por Gino Germani en Argentina, la sociología de Gonzáles Casanova tejió explícitos puentes con el marxismo para el abordaje de los "grandes problemas nacionales" del concepto de populismo en México guardó algunas similitudes con el que este había tenido durante sus primeros años de gestación en Argentina.

Para Córdova, la especificidad del populismo mexicano se vinculaba a la permanencia y legitimidad de instituciones políticas, que "están en la base" del "proceso autoritario", y que al mismo tiempo "consagran las reformas sociales"45. Era precisamente la imbricación entre estabilidad y legitimidad institucional, atada a la dimensión autoritaria del régimen político aquello que, diferenciaba

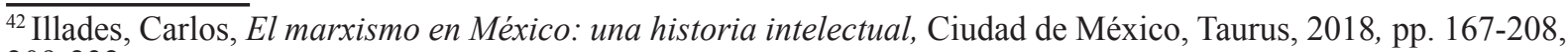
209-232.

${ }^{43}$ Nexos contaba con un "núcleo minoritario de intelectuales socialistas" y "decantó hacia posturas neoliberales durante el gobierno de Carlos Salinas de Gortari (1988-1994)" (Ibídem, p. 265). Para un estudio de esta franja de intelectuales críticos a través de sus revistas ver: Illades, Carlos, La inteligencia rebelde: la izquierda en el debate público en México 1968-1989, México, Océano, 2012.

${ }^{44}$ Ver, por ejemplo, González Casanova, Pablo, La democracia en México, México, Era, 1965.

${ }^{45}$ Córdova, Arnaldo, La formación ... op . cit., p. 61.
} 
"el populismo mexicano, que tiene a sus espaldas una revolución, del populismo de otros países de América Latina, por ejemplo, el populismo varguista en Brasil o el populismo peronista en la Argentina. En estos casos el populismo no se ha hecho sistema institucional y ha dependido fundamentalmente de la personalidad carismática de sus líderes"46.

El argumento de Córdova era este: México, como otros países de la región, era un país dependiente. Pero la asimetría en las relaciones económicas, políticas y culturales con los países desarrollados era especialmente significativa en México por su histórica relación con Estados Unidos. Esa dependencia (histórico-estructural) nunca había sido desmantelada. Como movilización popular y campesina la Revolución Mexicana (1910-1920) había tenido un momento rupturista demasiado fugaz y pronto devino en la institucionalización de su contrario, el avance de la clase capitalista. El populismo había sido la respuesta que el régimen político mexicano había encontrado para profundizar y complejizar la dependencia e instaurar un Estado aparentemente "popular, democrático, socialista y nacionalista".

Subsiste en la interpretación de Córdova una denuncia que trasciende tanto al período de hegemonía oligárquica (porfirismo, 1876-1911), a la Revolución Mexicana propiamente dicha y al Estado postrevolucionario: el poder político en México ha seguido, amén de la Revolución, una lógica autoritaria y personalista.

\footnotetext{
"En el porfirismo encontramos claramente una coincidencia, no casual, desde luego, sino necesaria, de dos hechos que, unidos, condicionan el desarrollo posterior de México: por un lado, el fortalecimiento del poder nacional mediante su transformación en poder personal y la sumisión, de grado o por la fuerza, de todos los elementos opuestos a este régimen, o la conciliación de los intereses económicos en una política de privilegios, de estímulos y de concesiones esenciales" ${ }^{\prime 4}$.
}

El problema se agravaba aún más al considerar la estructura económica, ya que las dificultades que históricamente había atravesado el país (el subdesarrollo) confluían con la anomalía del "elemento político". En México, el Estado, más que el mercado, había sido el promotor y dinamizador del capitalismo ${ }^{48}$.

Esta tesis había sido enunciada con insistencia por los teóricos dependientitas como un rasgo propio del capitalismo periférico en América Latina, pero en un país como México donde la Revolución era considerada como un hito fundacional del Estado moderno, una interpretación continuista como la de Córdova requería de una concienzuda reflexión. Al momento de su intervención, la Revolución se debatía en el campo intelectual mexicano entre las interpretaciones producidas en clave oficial, las lecturas revisionistas y la mirada marxista. Para la primera

\footnotetext{
${ }^{46}$ Ibídem, p. 93.

${ }^{47}$ Córdova, Arnaldo, La formación ... op . cit., p. 13. Cursiva propia.

${ }^{48}$ Ibídem, p. 10
} 
postura, la Revolución Mexicana había sido el producto de un genuino movimiento popular, campesino, agrario y nacionalista que derrocó a la oligarquía porfirista y cuyo principal legado fue la ruptura con dicho orden para la constitución de un Estado postrevolucionario democrático y socialista, aunque con períodos de mayor o menos acercamiento a ese legado. La corriente revisionista en su versión más "radical" insistía en "negar el carácter popular" de la Revolución y sostenían que su principal resultado había sido la institución de una suerte de Leviatán que poco o nada tenía que ver con las banderas levantadas por Villa y por Zapata. Mientras que la perspectiva marxista argumentaba que la Revolución efectivamente había sido producida por clases populares, el campesinado en su mayoría; por lo que su principal dilema fue explicar críticamente los efectos posteriores al período revolucionario: el Estado postrevolucionario ${ }^{49}$. Córdova construyó una interpretación que se opuso a la primera versión (oficialista o la revolución mitificada) y que discutió con la segunda y la tercera mirada (revisionista y marxista).

El autor distinguía tres tipos de revoluciones: revoluciones políticas, sociales y populares. Las primeras, conformaban el típico proceso de cambio inaugurado con la Revolución Francesa, transformaciones orientadas a "destruir un poder político, que, como el feudal, se confunde directamente con la propiedad, haciendo de ella una propiedad privilegiada" ${ }^{50}$. En el lenguaje marxista estas son revoluciones democrático-burguesas, levantamientos de la burguesía contra la nobleza. Las segundas, las revoluciones sociales, avanzan en la "transformación [...] de las relaciones de propiedad" 51 e implican la eliminación de la propiedad privada. El tercer tipo de revolución, las populares, suponen una tipología revolucionaria "nueva" ${ }^{52}$, aunque en realidad son revoluciones sociales ya que persiguen la abolición de la propiedad privada, y se desarrollan en manos de clases trabajadoras explotadas (clases populares). De estas últimas se desprende un subtipo, las revoluciones agrarias, las cuales no serían más que un hibrido o una "parte programática de una revolución social" ${ }^{153}$.

Para Córdova, subsistía un problema en esta tipología revolucionaria que se derivaba especialmente de la teoría marxista; pues "aqui [en América Latina], no sólo la teoría de la revolución, sino incluso toda la teoría política y la teoría social deberían ser inventadas desde el principio" ${ }^{\circ 5}$. ¿Podía caracterizarse al proceso revolucionario iniciado en México a comienzos del siglo xx como una revolución social y agraria? ¿O dicho proceso respondía a una revolución política tendiente a desmantelar el régimen feudal (revolución democrático-burguesa)? Y, si esto era cierto, ¿era el modo de producción feudal el que había generado condiciones objetivas para la Revolución en México? o ¿nos encontrábamos ante un nuevo tipo de relaciones sociales

\footnotetext{
${ }^{49}$ Sigo aquí la clasificación de Alan Knight. Ver: Knight, Alan, Revolución, Democracia y Populismo en América Latina, Santiago de Chile, Centro de Estudios Bicentenario, 2005; y Knight, Alan, "Interpretaciones recientes de la Revolución Mexicana”, en Secuencia, 13 (1989), pp. 23-43.

${ }^{50}$ Córdova, Arnaldo, La formación... op. cit., p. 24.

${ }^{51}$ Ibídem, p. 25.

${ }^{52}$ Ibídem, p. 24.

${ }^{53}$ Ibídem, p. 26.

${ }^{54}$ Ibídem, p. 27. Cursiva propia.
} 
y económicas? Para responder a estas preguntas Córdova partía de una premisa: la condición de dependencia estructural de México no podía ni debía "confundirse con el régimen social del feudalismo" "55. Bajo el prisma de Córdova, la teoría marxista era clave para definir el contenido esencial de una "verdadera revolución", esto es, la abolición de la propiedad privada, pero resultaba insuficiente para comprender la realidad latinoamericana, confundiendo dependencia con feudalismo.

Con la Revolución Mexicana, la estructura de dominación capitalista no se había modificado, pero sí se habían introducido reformas que complejizaban las condiciones objetivas y subjetivas para la verdadera revolución social. En primer lugar, durante el período postrevolucionario se había destruido "la vieja clase terrateniente" y se asistió a la aparición "en el campo de una gran masa de pequeños productores (propietarios o poseedores)" ${ }^{" 56}$. En segunda instancia, la diferencia "entre el porfirismo y el régimen postrevolucionario" consistía en las reformas incluidas en la nueva Constitución de 1917 (reforma agraria, justicia social y derechos laborales). Pero, en la práctica "las reformas sociales fueron empleadas como instrumentos del poder; [...] constituyeron un eficacísimo dique contra toda clase de explosiones revolucionarias que tuvieran raíces sociales" ${ }^{57}$. Durante el cardenismo, se había avanzado en la profundización de la reforma agraria y los derechos laborales y sociales, pero más que por sus reformas, en la historia de la Revolución Mexicana, el cardenismo se distinguía por el modo en que las llevó a cabo, esto es, por su política de masas ${ }^{58}$. "Y lo notable [...] fue que el cardenísimo no inventó esa línea de masas; simplemente reconstruyó la política revolucionaria misma y aplicó sus postulados, uno de los cuales, el esencial, consistía en que las tareas de la revolución no podían sino ser obra de las propias masas trabajadoras, bajo la dirección de los revolucionarios" ${ }^{59}$.

La operación intelectual de Córdova consistió en vincular, en una suerte de catacresis $^{60}$, dos conceptos opuestos y disponibles en el lenguaje político del período para referirse a un fenómeno que, entonces, carecía de un término específico. En palabras del autor, se trataba de "una forma, inédita en la historia, [...] una revolución populista"61.

Decimos que el concepto carecía de un referente histórico claro, pues el debate sobre el populismo en América Latina rondaba en torno a la definición de estos fenómenos como el resultado de la instauración de regímenes tipificados como autoritarios, articulados por líderes definidos como carismáticos y demagógicos (los casos más referenciados eran el varguismo

\footnotetext{
${ }^{55}$ Ibídem, p. 26.

${ }^{56}$ Ibídem, p. 16.

${ }^{57}$ Ibídem, pp. 21-22. Cursiva propia.

${ }^{58}$ Córdova, Arnaldo, La política de masas... op. cit.

${ }^{59}$ Córdova, Arnaldo, "Los maestros rurales en el cardenismo", en Cuadernos Políticos, 2 (1974), p. 77. Cursiva propia.

${ }^{60}$ La catacresis es una figura retórica que se caracteriza por el uso de un "nombre figural para el no existe contraparte literal". Laclau, Ernesto, Nuevas reflexiones sobre la revolución de nuestro tiempo, Buenos Aires, Ediciones Nueva Visión, 2000, p. 76. El ejemplo utilizado por Laclau es el de las "alas de del avión" o "las alas de un edificio", para mostrar el modo en que opera este tipo de figura retórica, pues, ni los edificios ni los aviones tienen literalmente "alas".

${ }^{61}$ Córdova, Arnaldo, La formación ... op. cit., p. 32.
} 
en Brasil y el peronismo en Argentina); o, en su defecto, como el producto de revoluciones sociales frustradas (el caso típico era Colombia). El concepto de revolución populista, abrió el debate a un nuevo modo de acceso al poder en los populismos. Ya no se trataba de un régimen gestado por un líder que había "manipulado a las masas" para elevarse en el poder, sino de un movimiento popular y revolucionario que se institucionalizó bajo "el populismo", esto es, bajo formas autoritarias e institucionalizadas.

En el concepto de Córdova habitaban implícitamente otros dos: revolución verdadera y dependencia. Ninguna revolución podía caracterizarse como tal si no cumplía con ciertas condiciones fundamentales: (a) debían desarrollarse autónomamente por la clase obrera o por clases populares; (b) dichas movilizaciones debían llegar a la toma efectiva del poder, de lo contrario quedaban en el camino como revoluciones espurias; (c) en el momento de institucionalización la propiedad privada debía abolirse así como las asimétricas relaciones de dependencia estructural con los países centrales ${ }^{62}$. De modo que, por contraste con la Revolución realmente existente, México aún esperaba un verdadero proceso revolucionario. Ambos significantes, revolución y dependencia, funcionan como premisas definidas de antemano y en función de las cuales se observaba el fenómeno mexicano, este no se apartaba de la trayectoria regional, sino que se inscribía en ella a través de una nueva tipología de populismo.

La resustancialización del concepto de revolución, eliminaba varias experiencias del "listado revolucionario" latinoamericano. La primera condición, descartaba a todos los procesos reformistas iniciados desde el Estado o por algún líder político (más o menos carismático o personalista). Los intentos revolucionarios "fallidos" o que no habían llegado a la toma efectiva del poder, como el de Colombia en 1948, también quedaban fuera de la tipología revolucionaria (segunda condición). Finalmente, aquellos procesos que sí habían cumplido al menos provisoriamente con la primera y la segunda condición (autonomía política y toma del poder, respectivamente), pero que no llegaron a institucionalizarse autónomamente en el Estado o no avanzaron en la consecución del contenido esencial de la revolución (tercer requisito), también quedaban descartados; el ejemplo era México. Allí, la Revolución había gozado de autonomía popular solo en un momento inicial, dirá Córdova. Los “exponentes revolucionarios de las clases medias" fueron los que "inventaron el populismo, no tanto en lucha contra el sistema oligárquico" sino "en lucha contra el movimiento campesino independiente que comandaban Villa y Zapata"63. En México se había dado "el centavo para ganar el peso"64. En última instancia, Córdova hacía de la Revolución Mexicana un hito fundacional del proceso contrarrevolucionario que se extendía hasta el presente en el país periférico más próximo a la cabeza del imperio estadunidense. La entraña contrarrevolucionaria del populismo se había

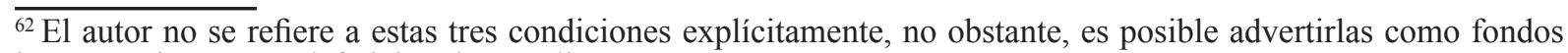
interpretativos en su definición de populismo.

${ }^{63}$ Córdova, Arnaldo, La formación ... op. cit., p. 32.

${ }^{64}$ Ibídem, p. 32.
} 
desarrollado en México precisamente para "evitar que el movimiento de masas se transformara en una revolución social" efectiva ${ }^{65}$.

\section{Hallazgos y conclusiones preliminares}

Desde el punto de vista del análisis sincrónico que aquí realizamos sobre la emergencia del concepto de populismo y su imbricación al de revolución en México, es posible señalar algunas conclusiones preliminares, tensiones e innovaciones que durante los años setenta se introdujeron en relación al modo de producción conceptual que caracterizaría al siglo xx. Por un lado, durante esta década aquella gramática que hizo posible la institución de una suerte de subjetividad militante asumiría características radicalizadas, al punto de suponer que el devenir político de la región dependía, en última instancia, de la identificación de ciertos sujetos y colectivos ("las clases populares", "el pueblo campesino", "el pueblo periférico") con su papel decisivo en la lucha revolucionaria y la liberación latinoamericana. Este sentido fue emparentado a un proceso de resustancialización del concepto de revolución, aunque esta ya no remitiría a una dimensión abstracta cuyo devenir excedía a los sujetos, sino a un proceso de cambio estructural de gran envergadura que indefectiblemente los involucraba. Lejos de inhibir la acción subjetiva, develar los condicionamientos estructurales del subdesarrollo, la dependencia y la política real se convirtieron durante estos años en una cuestión crucial para producir un cambio social, cultural, político y económico de características inéditas. Esas discusiones habilitaron la emergencia del concepto de populismo en países en los que el sistema político se apartaba de aquellas experiencias que habían dado lugar a los denominados "populismos clásicos". En México ello supuso una concienzuda reflexión sobre su "singularidad" cuestión que fue puntualizada en dos rasgos distintivos: el "origen revolucionario" del populismo y su carácter perdurablemente institucionalizado, en comparación con experiencias que se habían gestado desde el Estado y que habían sido tipificadas como personalistas o menos institucionalizadas (Argentina y Brasil) $^{66}$. Por ello, la emergencia del concepto en México supuso la gestación de interpretaciones especialmente críticas del principal acontecimiento revolucionario de principios de siglo xx. La Revolución Mexicana debía dejar de ser la marca distintiva de las revoluciones populares exitosas latinoamericanas para que "definitivamente" el país rompiera con el populismo y accediera a la lucha por la revolución verdadera. Posteriormente, ese

\footnotetext{
${ }^{65}$ Ibídem, p. 32.

${ }^{66}$ Recientemente estas ideas han sido fuertemente discutidas en Argentina. Ver, por ejemplo, Aboy Carlés, Gerardo, "Las dos caras de Jano: acerca de la compleja relación entre populismo e instituciones políticas", en Pensamiento plural, 7 (2010), pp. 21-40. «http://pensamentoplural.ufpel.edu.br/edicoes/07/02.pdf» [consultado el 26 de noviembre de 2018].
} 
horizonte sería menos probable, desplazando a escala regional el debate entre populismo y revolución a la disyuntiva entre populismo y democracia.

Ahora bien, más que reafirmar la singularidad del populismo mexicano de nuestro análisis se desprende otra cosa. La reactivación constante de los debates en torno a la cuestión populista en México y en América Latina pone de manifiesto la imposibilidad de fijar esencialmente su genética; caso por caso, el populismo ha servido para nombrar aspectos irreductibles e insistentemente problematizados en cada comunidad, nudos-problemas de las democracias modernas que el populismo vendría a iluminar.

Finalmente, a partir de este trabajo se identifican algunos interrogantes que deberán profundizarse a futuro, entre ellos señalaremos dos: ¿qué papel jugó la lógica de la Guerra Fría en la emergencia de nuevas formas de significación de lo político en la región? Y en un plano teórico, cabría indagar si más que "un" lenguaje político que caracterizaría a todo el siglo xx, lo que el análisis sincrónico alerta es la superposición de más de una gramática disponible. 